DOI: $10.2478 /$ ace-2013-0012

\title{
ESTIMATION OF AIR POLLUTANT EMISSIONS IN FLOWER ROUNDABOUTS AND IN CONVENTIONAL ROUNDABOUTS
}

\author{
F. CORRIERE ${ }^{1}$, M. GUERRIERI ${ }^{2}$, D. TICALI ${ }^{3}$, A. MESSINEO $^{4}$
}

\begin{abstract}
The road pollutant emissions, above all in urban context, are correlated to many infrastructural parameters and to traffic intensity and typology. The research work on road junction geometry, carried out in European research centres, has recently allowed to design new road intersection types which are of undoubted interest, especially in terms of traffic functionality and safety, like the flower roundabouts (in which right-turn manoeuvres do not conflict with the circulating flow). The main objective of this paper is to propose a model for the estimation the capacity, delay, levels of service and the pollutant emissions into flower roundabouts. A comparative analysis between conventional roundabout and flower roundabout has been carried out in terms of $\mathrm{CO}, \mathrm{CO}_{2}, \mathrm{CH}_{4}, \mathrm{NO}$, $\mathrm{PM}_{2,5}$ and $\mathrm{PM}_{10}$ vehicular emissions, evaluated by mean of COPERT Software which is developed as a European tool for the calculation of emissions from the road transport sector.
\end{abstract}

Keyword: Flower roundabouts, conventional roundabouts, capacity, delay, pollutant emissions.

\section{INTRODUCTION}

Flower roundabouts (see Figure 1 and 2) were designed and patended at the University of Maribor with the ambitious objective of gathering the positive aspects of the different types of roundabout intersections and, at the same time, eliminating the negative ones $[1,2,3]$, in other words getting the safety level better than conventional and turbo roundabouts without reducing capacity. As a matter of fact, a flower roundabout is a roundabout with two lanes at entries, two lanes at exits and a ring lane which makes right-turning vehicles get onto a free-flowing bypass lane, and not into the ring. From this viewpoint, flower roundabouts are not a novelty at all in the panorama of road intersections but they are rather simply a specific type of conventional roundabout with a ring lane, a lane at entries and an additional lane to turn on the right (an example of

1 Associate Professor, Faculty of Engineering, University of Palermo, Italy, e-mail: ferdinando.corriere@unipa.it

2 Researcher, University of Enna "Kore" - Adjunct Professor at University of Palermo, Italy, Via delle Madonie 21, 90114 Palermo (Italy), e-mail: marco.guerrieri@tin.it, (Corresponding Author)

3 Assistant Professor, Faculty of Engineering and Architecture, University of Enna "Kore", Italy, e-mail: dario.ticali@unikore.it

4 Assistant Professor, Faculty of Engineering and Architecture, University of Enna "Kore", Italy, e-mail: antonio.messineo@tin.it 
roundabout with Right-Turn Bypass Lanes, is shown in Figure 3). The interior roadside of the latter lane is separated from the outside edge of the circulatory carriageway by a pseudo-elliptical traffic island, whose maximum width is equal to the circulatory carriageway width. As far as safety matters are concerned [4], it is worth pointing out that there are no weaving in circulatory roadway but only eight conflict points (more exactly, 4 diverging points and 4 merging points) which characterize a conventional roundabout with a ring lane. As to bypass lanes, it is also required to calculate the diversion points concerning the right-turn routing manoeuvre and the entry points in the flow from the roundabout. These conflict points are located at a certain distance from the roundabout, where the effect on speed limitation is less noticeable. Therefore, on one hand there is the advantage of eliminating switch manoeuvres (that, in case of two-lane roundabouts, take place in the ring at moderate speed), on the other hand, there is the disadvantage of introducing diverging and merging conflict points away from the roundabout. On the whole, a flower roundabout is characterized by 16 conflict points: 8 diverging points and 8 merging points [5]. Another crucial aspect of flower roundabouts is related to the alternation of sign and value of the axis curvatures of the lane specialized for the right turn with visible negative effects on driving comfort and safety. The geometric defect could be easily corrected by implementing a bypass with a curvature of the same sign as in the entire development; however, in doing so, the resulting scheme is clearly no more a flower roundabout. In short, flower roundabouts have neither weaving areas along the ring, nor through points in circulating flows (as it occurs instead in turbo roundabouts), the encumbrances are similar to those in two-lane roundabouts, but they have the disadvantage of diverging and merging points in the arms and also right-turn lanes (bypass) implemented by means of circumference arcs with curvatures of opposite signs. On the possibility of converting existing double lane roundabouts to flower roundabouts, it is suggested to pay attention because in many traffic condition could be significant capacity reductions at entries.

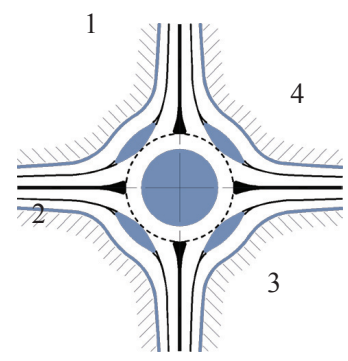

Fig. 1. Flower Roundabouts layout

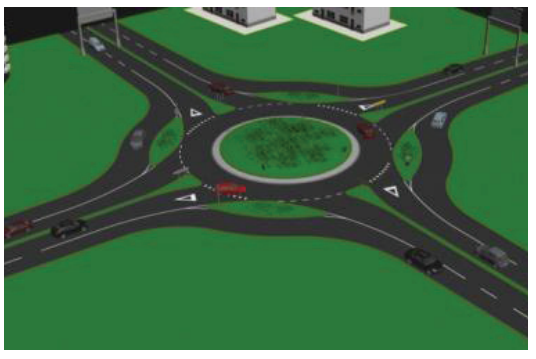

Fig. 2. Flower Roundabouts rendering [2]

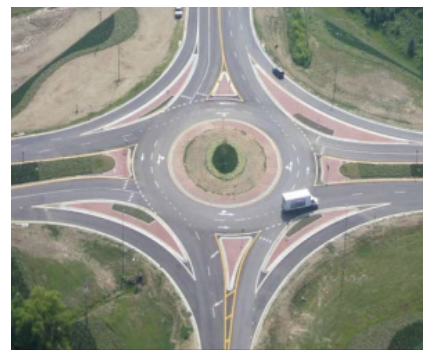

Fig. 3. Conventional Roundabouts with bypass lane

This paper presents a model for estimation the capacity, delay, queue and pollutant emissions at flower roundabouts. Also, has been carried out specific traffic analyses with the objective to identify the benefits of innovative roundabouts respect to con- 
ventional intersections in terms of air pollution emission. The procedure developed is shown in the following Flowchart (cf. Fig. 4).

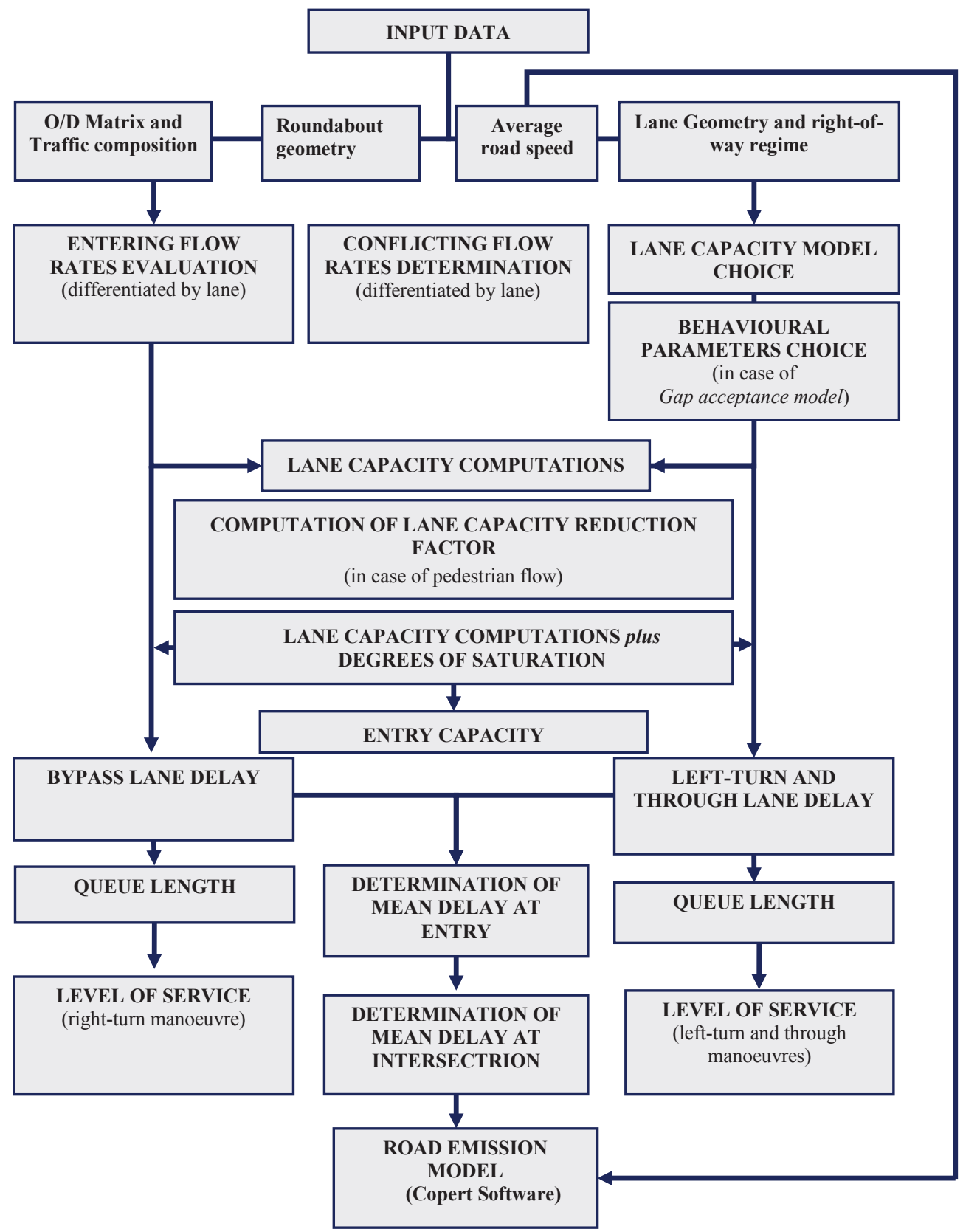

Fig. 4. Functional and pollutant emissions analysis flowchart for flower roundabouts 


\section{CAPACity estimation}

\subsection{ENTRY LANE CAPACITY}

Roundabout entries have two traffic lanes: the former lane for through and left-turn manoeuvres; the latter for right-turn manoeuvres. The entry flow from $\operatorname{arm}\left(\mathrm{Q}_{\mathrm{E}}\right)$ can be, therefore, divided into two distinct rates ( $c f$. Fig. 5):

- Through and left-turn flow $\mathrm{Q}_{\mathrm{E}, \mathrm{TLT}}$;

- Right-turn flow $\mathrm{Q}_{\mathrm{E}, \mathrm{R}}$.

Moreover, in through and left-turn flow the conflicting circulating flow is the one in front of the arm under examination $\left(\mathrm{Q}_{\mathrm{c}}\right)$ which has priority, while in the right-turn flow involving a slip lane, it is the one exiting from the destination $\operatorname{arm}\left(\mathrm{Q}_{\mathrm{u}}\right)$, calculated net of the same right-turn flow $\left(\mathrm{Q}_{\mathrm{E}, \mathrm{R}}\right)$. If we consider the specialization in entry lanes as well as the diverse values of entry and conflicting flows, it is necessary to estimate lane capacities separately.

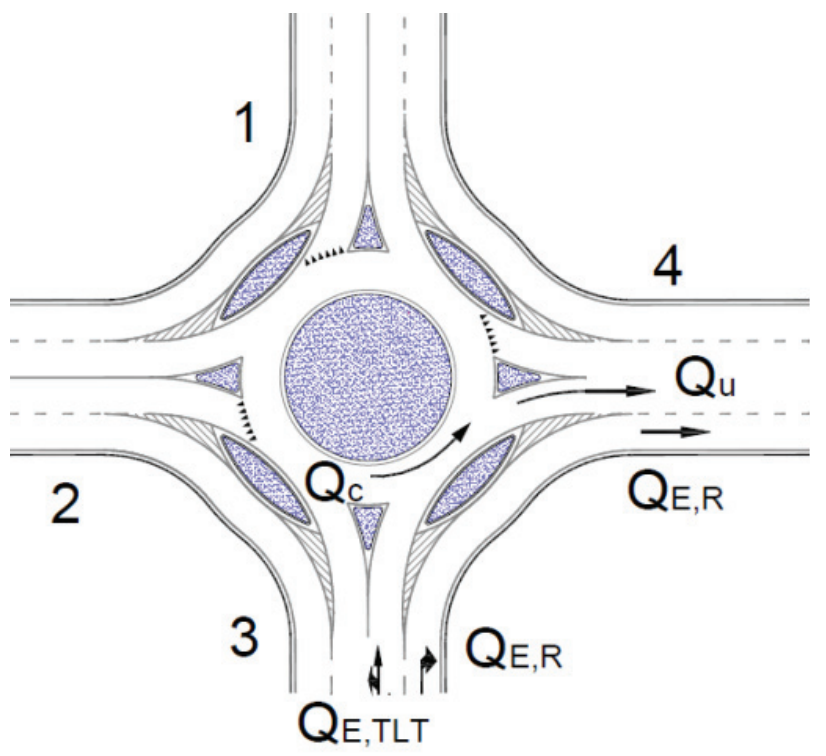

Fig. 5. Entry and exit flows at flower roundabout

Therefore, the methodological approach to determine entry capacities is similar to the one adopted in turbo roundabouts $[6,7,8]$ which requires a lane by lane analysis owing to the physical separation of traffic lanes. More recently, the Manual HCM 2010 [9] has extended the lane-by-lane analysis method to traditional roundabouts, thus conforming to Akçelik's research results [10]. From the above considerations, the capacities of through and left-turn lanes $\left(\mathrm{C}_{\mathrm{E}, \mathrm{TLT}}\right)$ and right-turn bypass lane $\left(\mathrm{C}_{\mathrm{E}, \mathrm{R}}\right)$ can be estimated, under stationariness conditions of vehicle flow, by means of different models. 
In the case of the slip lane are possible three different traffic regulations: Stop, Yeld and Free Flow.

\section{Right-turn bypass lane with Stop signal [11]:}

$$
\mathrm{C}_{\mathrm{E}, \mathrm{R}}=1231,4 \cdot \mathrm{e}^{-0,0012 \cdot \mathrm{Qu}}
$$

Yelding bypass lane [10], [11], [12]:

$$
\mathrm{C}_{\mathrm{E}, \mathrm{R}}=1130 \cdot \mathrm{e}^{-0,001 \cdot \mathrm{Qu}}
$$

Free Flow bypass lanes [13], [14], [15]:

$$
\mathrm{C}_{\mathrm{E}, \mathrm{R}}=1250 \cdot \mathrm{e}^{-0,0007 \cdot \mathrm{Qu}}
$$

The HCM 2010 capacity model has been adopted for the left-turn bypass lane $\left(\mathrm{C}_{\mathrm{E}, \mathrm{TLT}}\right)$ :

$$
C_{E, T L T}=1130 \cdot e^{\left(-1,0 \cdot 10^{-3}\right) \cdot Q_{c}}
$$

where:

$\mathrm{Qc}_{\mathrm{pce}}=$ circulating flow in front of the entry $[\mathrm{pc} / \mathrm{h}]$

$\mathrm{Qu}_{\mathrm{pce}}=$ flow exiting from the next arm after the entry subject to capacity estimation $[\mathrm{pc} / \mathrm{h}]$

Qc = circulating flow in front of the entry [veh $/ \mathrm{h}$ ]

$\mathrm{Qu}=$ conflicting flow, exiting from the next arm after the entry subject to capacity estimation $[\mathrm{veh} / \mathrm{h}]$

It is worth observing that the capacity values of the ring which has a single lane, are close to $1,600 \mathrm{veh} / \mathrm{h}[5,16]$.

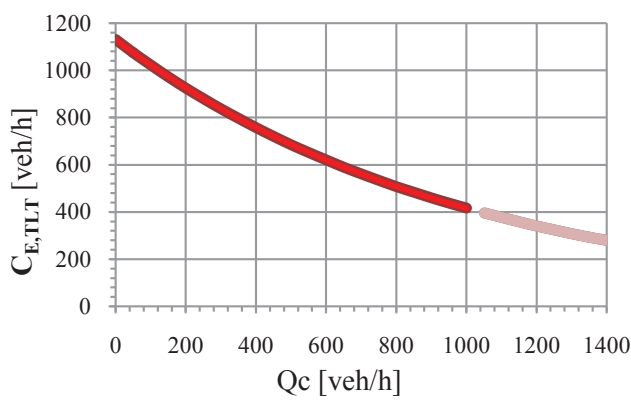

Fig. 6. Entry Through and left-turn lane capacity

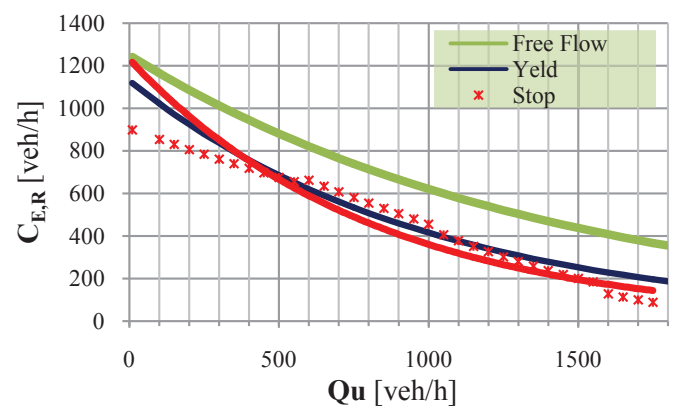

Fig. 7. Right-turn lane capacity [11] 


\subsection{The Effect Of Pedestrian Flows}

According to the German method [17], the analysis of the pedestrian flow effect on the entry capacity of flower roundabouts can be obtained as follows:

$$
\mathrm{C}_{\mathrm{E}, \mathrm{R}}^{\text {ped }}=\mathrm{C}_{\mathrm{E}, \mathrm{R}} \cdot \mathrm{M}_{\mathrm{E}, \mathrm{R}}
$$

$$
\mathrm{C}_{\mathrm{E}, \mathrm{TLT}}^{\text {ped }}=\mathrm{C}_{\mathrm{E}, \mathrm{TLT}} \cdot \mathrm{M}_{\mathrm{E}, \mathrm{TLT}}
$$

(7) $\mathrm{M}_{\mathrm{E}, \mathrm{R}}=\left(1119,5-0,715 \cdot \mathrm{Q}_{\mathrm{u}}-0,644 \cdot \mathrm{Q}_{\mathrm{ped}}+0,00073 \cdot \mathrm{Q}_{\mathrm{u}} \cdot \mathrm{Q}_{\mathrm{ped}}\right) /\left(1069-0,65 \cdot \mathrm{Q}_{\mathrm{u}}\right)$

(8) $\mathrm{M}_{\mathrm{E}, \mathrm{TLT}}=\left(1119,5-0,715 \cdot \mathrm{Q}_{\mathrm{c}}-0,644 \cdot \mathrm{Q}_{\mathrm{ped}}+0,00073 \cdot \mathrm{Q}_{\mathrm{c}} \cdot \mathrm{Q}_{\mathrm{ped}}\right) /\left(1069-0,65 \cdot \mathrm{Q}_{\mathrm{c}}\right)$

where:

$\mathrm{Q}_{\text {ped }} \quad=$ pedestrian flow $[\mathrm{ped} / \mathrm{h}]$

$\mathrm{M}_{\mathrm{E}, \mathrm{R}} \quad=$ right-turn lane pedestrian capacity reduction factor;

$\mathrm{M}_{\mathrm{E}, \mathrm{TLT}}=$ through and left-turn lane pedestrian capacity reduction factor;

$\mathrm{C}_{\mathrm{E}, \mathrm{R}}$ ped = right-turn lane vehicle capacity, impact of pedestrians considered [veh/h];

$\mathrm{C}_{\mathrm{E}, \mathrm{TLT}}{ }^{\text {ped }}=$ through and left-turn lane vehicle capacity, impact of pedestrians considered $[\mathrm{veh} / \mathrm{h}]$

$\mathrm{C}_{\mathrm{E}, \mathrm{R}}=$ right-turn lane vehicle capacity (no pedestrians crossing, only vehicles) [ve$\mathrm{h} / \mathrm{h}]$;

$\mathrm{C}_{\mathrm{E}, \mathrm{TLT}}=$ through and left-turn lane vehicle capacity (no pedestrians crossing, only vehicles) $[\mathrm{veh} / \mathrm{h}]$.

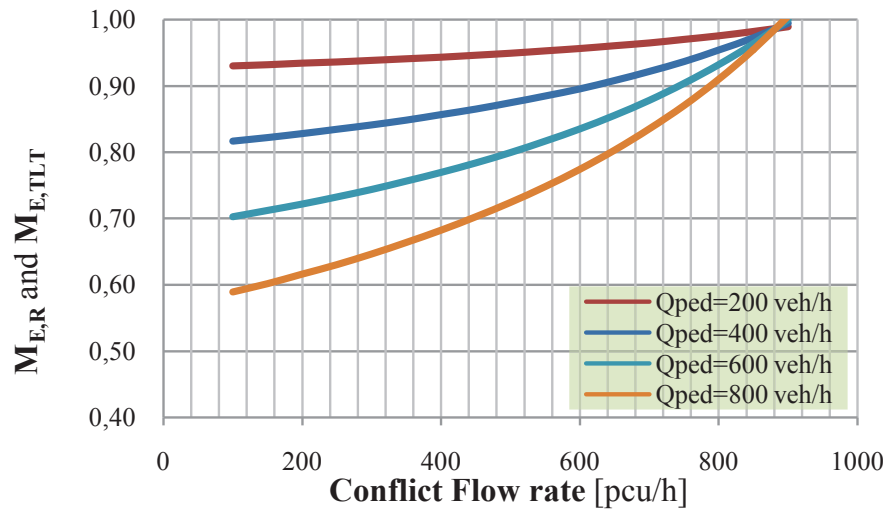

Fig. 8. Pedestrian capacity reduction factor $\left(\mathrm{M}_{\mathrm{E}, \mathrm{R}}\right.$ and $\left.\mathrm{M}_{\mathrm{E}, \mathrm{TLT}}\right)$ 


\subsection{ENTRY CAPACITY}

After estimating the single lane capacities, if we denote the saturation degrees (entry flow/capacity rate) with $\mathrm{x}$ and the relevant utilization degrees with $\rho$, the entry capacity $\mathrm{C}_{\mathrm{E}}$ (or $\mathrm{C}_{\mathrm{E}}$ ped in the case of pedestrian flow) can be determined by the following relations [4], [8]:

$$
\mathrm{x}_{\mathrm{E}, \mathrm{R}}=\frac{\mathrm{Q}_{\mathrm{E}, \mathrm{R}}}{\mathrm{C}_{\mathrm{E}, \mathrm{R}}{ }^{\text {ped }}}
$$

$$
\begin{gathered}
x_{E, T L T}=\frac{Q_{E, T L T}}{C_{E, T L T}{ }^{p e d}} \\
X=\operatorname{Max}\left(x_{E, R} ; x_{E, T L T}\right) \\
\rho_{E, R}=\frac{x_{E, R}}{X} \\
C_{E}{ }^{p e d}=\rho_{E, R} \cdot C_{E, R}{ }^{p e d}+\rho_{E, T L T} \cdot C_{E, T L T}{ }^{p e d} \\
C_{E}{ }^{\text {ped }}=\frac{\left(x_{E, T L T}\right.}{\left.\max _{E, R}+\frac{Q_{E, R}}{C_{E, R}{ }^{p e d}} \frac{Q_{E, T L T}}{C_{E, T L T}{ }^{p e d}}\right]}
\end{gathered}
$$

In a flower roundabout the entry capacity $\left(\mathrm{C}_{\mathrm{E}}\right.$ ped $)$ is function of the circulating flow in front of the entry under examination $\left(\mathrm{Q}_{\mathrm{c}}\right)$, the flow exiting from the next arm after that under analysis $\left(\mathrm{Q}_{\mathrm{u}}\right)$, the pedestrian flow $\mathrm{Q}_{\mathrm{ped}}$ and the saturation degrees of lanes. The graph illustrated in Fig.10 reports entry capacity values in a flower roundabout, worked out by varying circulating and exit flows (though satisfying the condition $\mathrm{Q}_{\mathrm{u}} \leq \mathrm{Q}_{\mathrm{c}}$ ), on the hypothesis that entry lanes have equal saturation degrees and $\mathrm{Q}_{\text {ped }}=0$ (in that case, the entry capacity is given by the sum of the capacity of the two lanes, $\mathrm{C}_{\mathrm{E}}=\mathrm{C}_{\mathrm{E}, \mathrm{R}}+\mathrm{C}_{\mathrm{E}, \mathrm{TLT}}, c f$. eq. 16). A microsimulation software has allowed to highlight how flower roundabouts, compared to traditional ones with two entry lanes and two ring lanes, can be advantageous in terms of capacity (and consequently vehicle delays) when most of the traffic entering the intersection turns on the right [2]; such a result is also confirmed by the analyses carried out in this paper. However, it is worth pointing out 
that such a circumstance is subject to a well-defined condition, that is the presence of circulating flows $(\mathrm{Qc})$ below or close to $1,600 \mathrm{veh} / \mathrm{h}$ (see Fig. 6). Should such a threshold be exceeded, even in correspondence with only one entry ( $\mathrm{Qc}>1,600 \mathrm{veh} / \mathrm{h}$ ), the ring would be under oversaturation conditions, and consequently the number of vehicles that can flow through the sections/lanes would reduce drastically towards to zero. For this reason, flower roundabouts can be applied to two clearly distinct fields as outlined below:

- Modest or moderate circulating flows (Qc $<1,600 \mathrm{veh} / \mathrm{h})$ : in some combinations of the distribution and intensity of entry flows, a flower roundabout can lead to higher entry capacities than conventional compact or large-sized roundabouts ( 2 ring lanes and 2 lanes at entries);

- High circulating flows (Qc $>1,600 \mathrm{veh} / \mathrm{h}$ ): a flower roundabout cannot be used; instead, a conventional large-sized roundabout (i.e. 2-ring lanes and 2-entry lanes) is more appropriate, in that its circulatory carriageway capacity can reach 2,500 $\mathrm{veh} / \mathrm{h}$.

\section{Estimation of delay, Queue and Level of Service}

After calculating the capacity and degree of saturation of each lane, in case of pedestrian flow, average control delay can be determined from the following equation [8], [9]:

$$
\begin{aligned}
& D_{E, R}{ }^{p e d}=\frac{3600}{C_{E, R}{ }^{p e d}}+900 \cdot T \cdot\left[\frac{Q_{E, R}}{C_{E, R}{ }^{p e d}}-1+\sqrt{\left.\left(\frac{Q_{E, R}}{C_{E, R} p^{p e d}}-1\right)^{2}+\frac{\left(\frac{3600}{C_{E, R}{ }^{p e d}}\right) \cdot\left(\frac{Q_{E, R}}{C_{E, R}}\right)}{450 \cdot T}\right)}\right]+5 \cdot \min \left[\frac{Q_{E, T L T}}{C_{E, T L T}{ }^{p e d}}, 1\right]
\end{aligned}
$$

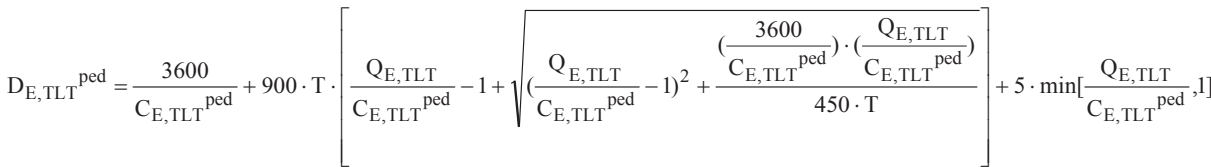

where: $D_{E, R}$ ped $=$ average delay for the single vehicle queuing at right-turn lane; $\mathrm{D}_{\mathrm{E}, \mathrm{TLT}}{ }^{\text {ped }}=$ average delay for the single vehicle queuing at through and left-turn lane; $\mathrm{T}=$ reference time (h).Generally speaking, delays will differ at the two entry lanes; so the level of service of the right-turn lane needs to be differentiated from the corresponding level of service at the through and left-turn lanes. Should global information be necessary, however, the calculation of the average delay at each lane can still help; an overall average delay can be obtained by giving different weights to these values according to their respective traffic demand. For instance, the performances at conventional intersections can be compared with those at turbo roundabouts, but the latter 
require a detailed evaluation at each lane. The overall average delay at entry $D_{E}$ is expressed by the following equation:

$$
D_{E}=\frac{D_{E, R}^{p e d} \cdot Q_{E, R}+D_{E, T L T}^{p e d} \cdot Q_{E, T L T}}{Q_{E, R}+Q_{E, T L T}}
$$

where $\mathrm{D}_{\mathrm{E}, \mathrm{R}}^{\text {ped }}, \mathrm{Q}_{\mathrm{E}, \mathrm{R}}, \mathrm{D}_{\mathrm{E}, \mathrm{TLT}}$ ped, $\mathrm{Q}_{\mathrm{E}, \mathrm{TLT}}$ are respectively delays and flow rates at the two lanes of entry E. The level of service as function of the delay are shown in Table 1 [7], [8], [9]. Figure 10 shows an example of the overall delay variation at entry in relation to the degree of saturation at each lane (no pedestrian flow).

Table 1

Level of service

\begin{tabular}{|c|c|c|}
\hline $\mathbf{D}_{\mathbf{E}}$ (mean delay) & $\mathbf{Q} / \mathbf{C} \leq \mathbf{1}$ & $\mathbf{Q} / \mathbf{C}>\mathbf{1}$ \\
\hline $0 \div 10(\mathrm{sec} / \mathrm{veh})$ & $\mathrm{A}$ & $\mathrm{F}$ \\
\hline $10 \div 15(\mathrm{sec} / \mathrm{veh})$ & $\mathrm{B}$ & $\mathrm{F}$ \\
\hline $15 \div 25(\mathrm{sec} / \mathrm{veh})$ & $\mathrm{C}$ & $\mathrm{F}$ \\
\hline $25 \div 35(\mathrm{sec} / \mathrm{veh})$ & $\mathrm{D}$ & $\mathrm{F}$ \\
\hline $35 \div 50(\mathrm{sec} / \mathrm{veh})$ & $\mathrm{E}$ & $\mathrm{F}$ \\
\hline$>50(\mathrm{sec} / \mathrm{veh})$ & $\mathrm{F}$ & $\mathrm{F}$ \\
\hline
\end{tabular}

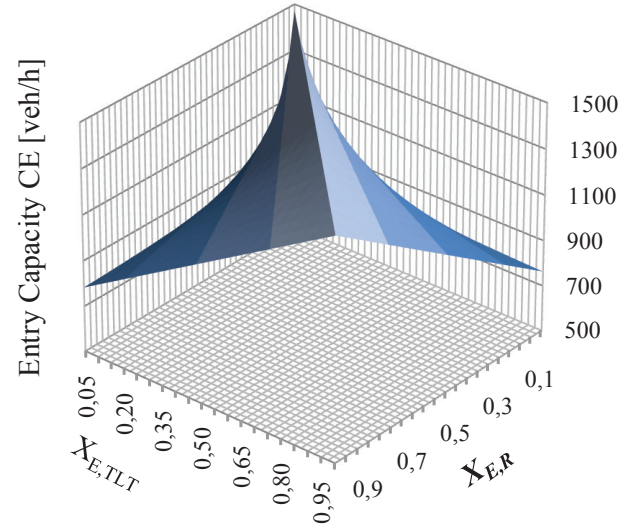

Fig. 9. Flower roundabout entry capacity

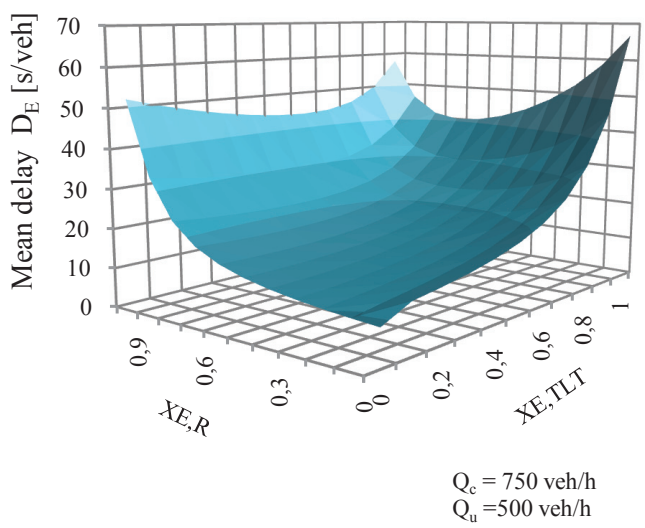

Fig. 10. Flower Average entry delay (no pedestrian flow) 
The 95th-percentile queue for the two lanes on an approach is calculated using the following equations [9], [18], [19], [20]:

$$
\mathrm{Q}_{(95)_{\mathrm{E}, \mathrm{TLT}}}=900 \cdot \mathrm{T} \cdot\left[\mathrm{x}_{\mathrm{E}, \mathrm{TLT}}-1+\sqrt{\left(1-\mathrm{x}_{\mathrm{E}, \mathrm{TLT}}\right)^{2}+\frac{\left(\frac{3600}{\mathrm{C}_{\mathrm{E}, \mathrm{TLT}}{ }^{\mathrm{ped}}}\right) \cdot \mathrm{x}_{\mathrm{E}, \mathrm{TLT}}}{150 \cdot \mathrm{T}}}\right] \cdot \frac{\mathrm{C}_{\mathrm{E}, \mathrm{TLT}}{ }^{\mathrm{ped}}}{3600}
$$

$$
\mathrm{Q}_{(95)_{\mathrm{E}, \mathrm{R}}}=900 \cdot \mathrm{T} \cdot\left[\mathrm{x}_{\mathrm{E}, \mathrm{R}}-1+\sqrt{\left(1-\mathrm{x}_{\mathrm{E}, \mathrm{R}}\right)^{2}+\frac{\left(\frac{3600}{\left.\mathrm{C}_{\mathrm{E}, \mathrm{R}}{ }^{\text {ped }}\right) \cdot \mathrm{x}_{\mathrm{E}, \mathrm{R}}}\right.}{150 \cdot \mathrm{T}}}\right] \cdot \frac{\mathrm{C}_{\mathrm{E}, \mathrm{R}}{ }^{\mathrm{ped}}}{3600}
$$

where: $\mathrm{Q}_{(95)}=95$ th-percentile queue, veh and $\mathrm{T}=$ time period, $\mathrm{h}(\mathrm{T}=1$ for a 1-h analysis, $\mathrm{T}=0.25$ for a 15 -min analysis).

\section{Estimation OF the pOlLUtANT EMISSIONS}

The pollutions emission can be carried out by mean of Copert Software which is developed as a European tool for the calculation of emissions from the road transport sector $[21,22,23]$. The model takes into account many traffic and vehicular parameters as: vehicle types, categories and population, annual mileage ( $\mathrm{km} / \mathrm{year})$, mean fleet mileage $(\mathrm{km})$, etc. (see. Fig. 11). The methodology allows to calculate the exhaust emissions of carbon monoxide (CO), nitrogen oxides (NOX), non-methane volatile organic compounds (NMVOC), methane $\left(\mathrm{CH}_{4}\right)$, particulate matter $(\mathrm{PM})$, and carbon dioxide $\left(\mathrm{CO}_{2}\right)$. The emission factor (EF) for each exhaust emission and for each transport modality $m$ is calculated by means of the following equation:

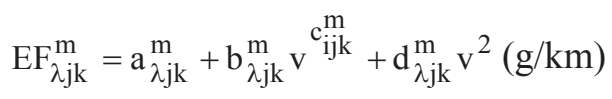

Where: $\lambda$ index is the age of the vehicles; $\mathrm{J}$ index is the fuels typology; $\mathrm{K}$ is the engine displacement; $\mathrm{a}, \mathrm{b}, \mathrm{c}$ are three parameters correlated to single pollution emission.

$$
\mathrm{EF}_{\lambda \mathrm{jk}}^{\mathrm{m}}=\mathrm{a}_{\lambda \mathrm{jk}}^{\mathrm{m}}+\mathrm{b}_{\lambda \mathrm{jk}}^{\mathrm{m}} \mathrm{v}^{\mathrm{c}_{\mathrm{ijk}}^{\mathrm{m}}}+\mathrm{d}_{\lambda \mathrm{jk}}^{\mathrm{m}} \mathrm{v}^{2}(\mathrm{~g} / \mathrm{km})
$$

The total emissions $\mathrm{E}_{\mathrm{i}}$ for the pollution $i$ can be calculated as:

$$
E_{i}=E F_{i} \cdot N_{i} \cdot \bar{p}_{i}(\mathrm{~g} / \text { year })
$$


Where: $\bar{p}_{i}$ is the mean length of the annual trip $[\mathrm{km}]$ and $N i$ is the number of annual vehicle belonging to the same emission group.

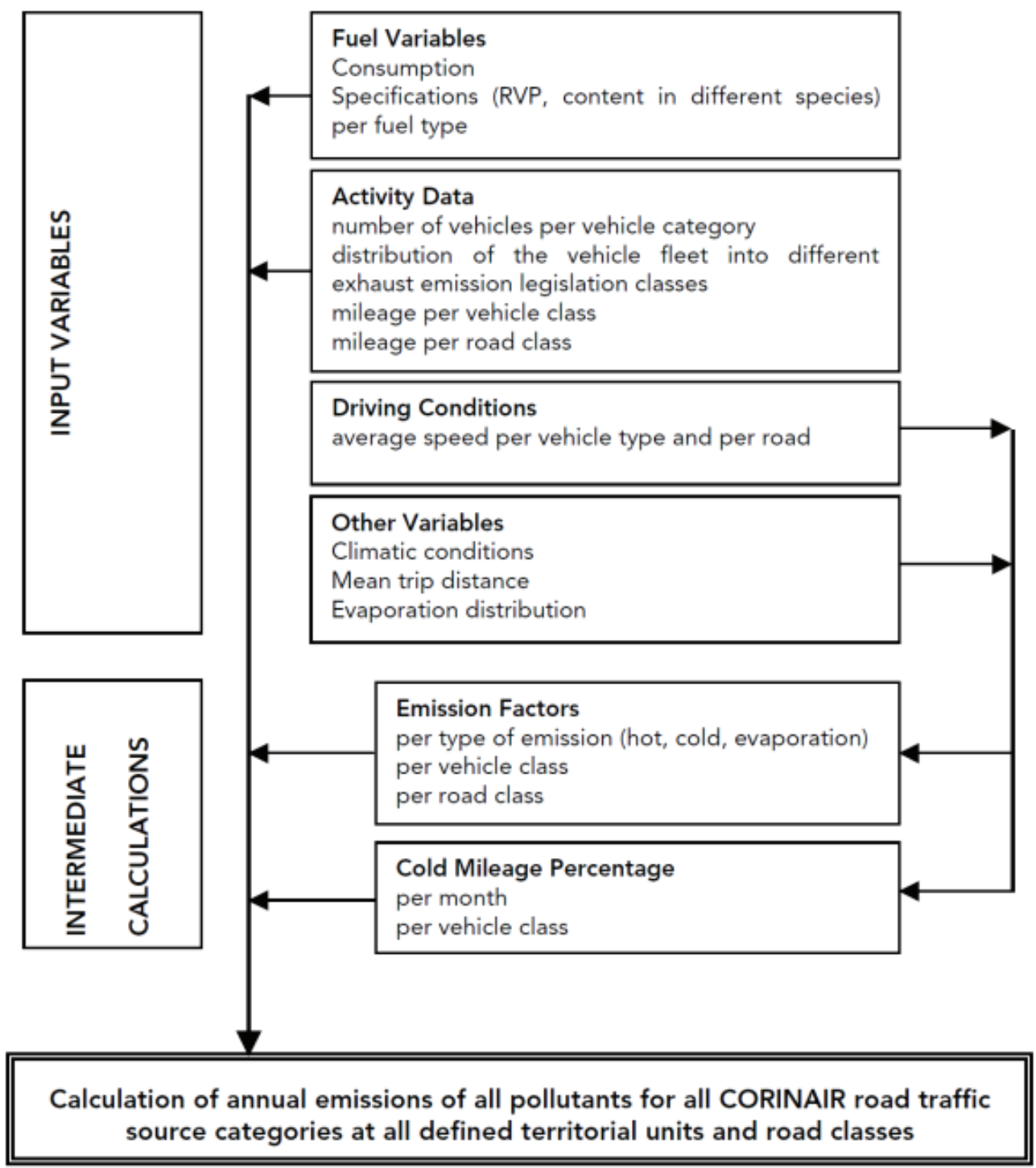

Fig. 11. Flow chart of the application of the Copert methodology 


\section{Functional and EnVironmental comparative analysis}

With the aim to identify the benefits of innovative roundabouts respect to conventional intersections [24] in terms of road pollution emission, specific traffic analyses have been carried out. The study regards six different geometrics layouts (cf. Figures 12-15) and many traffic flow conditions (both vehicular and pedestrian flows are taken into account). The road emission has been evaluated in the roads configuration reported in Figure 16 (the free flow speed value considered is $50 \mathrm{~km} / \mathrm{h}$ ).

The geometric layouts compared to one another are the following:

- Flower Roundabouts with stop-controlled slip lane;

- Flower Roundabouts with yield-controlled slip lane;

- Flower Roundabouts with Free-flow slip lanes;

- Conventional roundabouts with a single lane at entries and a single lane at the ring;

- Conventional roundabouts with a single lane at entries and a double lane at the ring;

- Conventional roundabouts with a double lane at entries and a double lane at the ring.

In order to determine the right lane capacities, the following formulations have been used:

- Eq. (1) for flower roundabouts with a stop-controlled slip lane

- Eq. (2) for Flower roundabouts with a yield-controlled slip lane

- Eq. (3) for Flower roundabouts with a free-flow slip lane

- The formula suggested by the HCM 2010 manual for conventional roundabouts with a single lane at entries and 1 lane at the ring:

$$
\mathrm{C}_{\mathrm{E}}=1130 \cdot \mathrm{e}^{-0,0001 \cdot \mathrm{Qc}}
$$

- The formula suggested by the HCM 2010 manual for conventional roundabouts with a single lane at entries and 2 lanes at the ring:

$$
\mathrm{C}_{\mathrm{E}}=1130 \cdot \mathrm{e}^{-0,007 \cdot \mathrm{Qc}}
$$

- The formulas suggested by the HCM 2010 manual for conventional roundabouts with a double lane at entries and a double lane at the ring: for the two lanes at entries the formulas are the following:

$$
\begin{aligned}
C_{E, R} & =1130 \cdot e^{-0,0007 \cdot Q c} \\
C_{E, T L T} & =1130 \cdot \mathrm{e}^{-0,00075 \cdot Q c}
\end{aligned}
$$

For each layout under study the mean control delays have been determined by employing equations (17), (18) and (19). The traffic conditions examined are the following: 


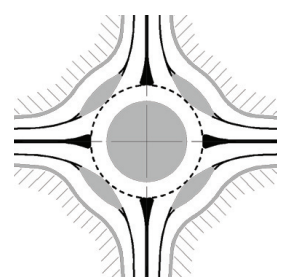

Fig. 12. Flower Roundabout

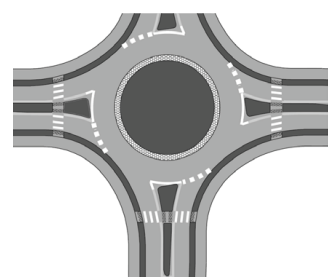

Fig. 13. Roundabout $(1+1)$

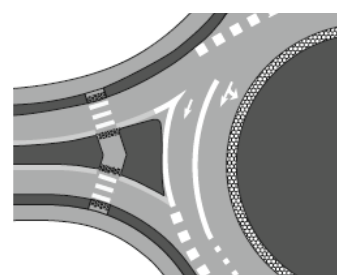

Fig. 14 Roundabout $(1+2)$

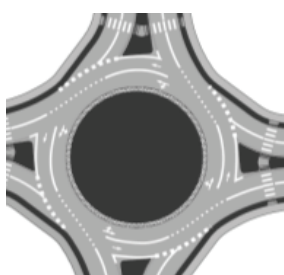

Fig. 15. Double lane Roundabout $(2+2)$

The Following hourly O/D Matrix, Vehicular and Pedestrian flow vectors have been analysed. This traffic conditions are indicatives of the daily hourly peak flows. The values of the total annul traffic flows are reported in Table 2.

$$
\begin{aligned}
& \rho=\left|\begin{array}{cccc}
0 & 0,15 & 0,74 & 0,11 \\
0,19 & 0 & 0,24 & 0,57 \\
0,63 & 0,15 & 0 & 0,22 \\
0,19 & 0,74 & 0,07 & 0
\end{array}\right|
\end{aligned}
$$

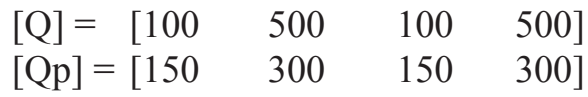

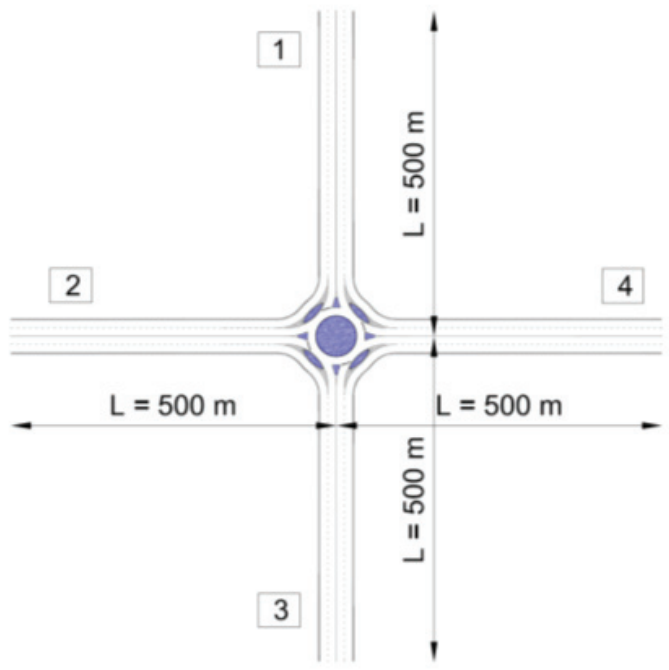

Figure 16. Road intercton layout 
The following graphics illustrate the values of mean control delay at roundabouts and the average speed as function of the intensity of entry flows. Obviously when the traffic value is very high the average speed is low. Flower Roundabouts and double lane roundabout are best solution respect to conventional roundabouts with scheme $(1+1)$ and $(1+2)$ (cf. Figures 17 and 18).

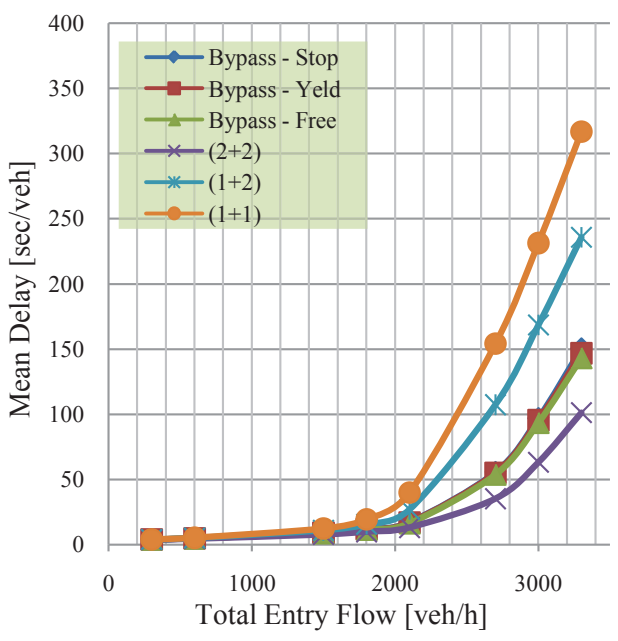

Fig. 17. Mean delay at intersection (Sceario: $\rho, Q, Q p$ )

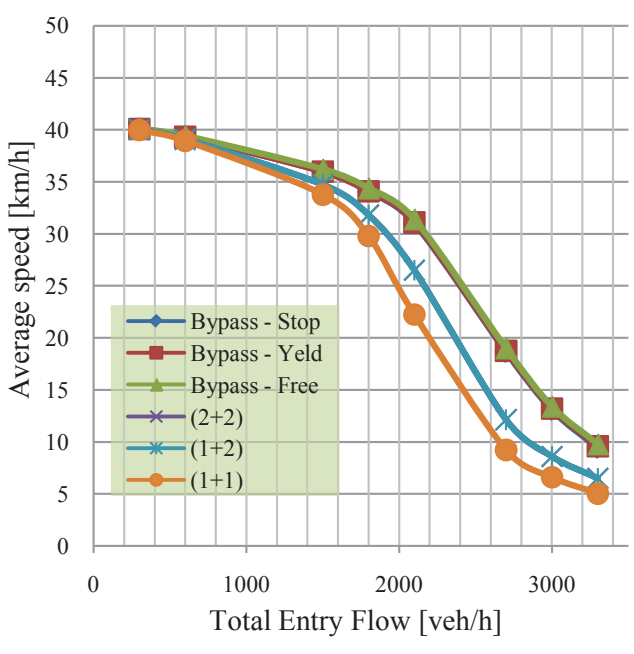

Fig. 18. Mean speed (Sceario: $\rho, Q, Q p$ )

The vehicles distribution that has been examined is the following:

- Passenger cars, Gasoline1,4 1 - 21 - Euro II;

- Passenger cars, Gasoline1,4 1 - 21 - Euro III;

- Passenger cars, Gasoline1,4 1 - 21 - Euro IV;

- Passenger cars, Diesel 1,4 1 - 21 - Euro II;

- Passenger cars, Diesel 1,4 1 - 21 - Euro III;

- Passenger cars, Diesel 1,4 1 - 21 - Euro IV;

- Heavy Duty Trucks $<7,5 \mathrm{t}$ - Euro II;

- Heavy Duty Trucks $<7,5$ t - Euro III;

- Heavy Duty Trucks $<7,5$ t - Euro IV.

The Figures 18-22, shown the results of the analysis for the $\mathrm{CO}, \mathrm{CO}_{2}, \mathrm{CH}_{4}, \mathrm{NO}$, $\mathrm{PM}_{2,5}$ and $\mathrm{PM}_{10}$ road emissions. In all cases the road emission increase with the Traffic flow. In the range $81000-450000 \mathrm{veh} /$ year there isn't a strong correlation between emissions and intersection geometric layout. But, if the value of $450000 \mathrm{veh} / \mathrm{year}$ is exceeded the road emissions are function of the roundabouts geometry; as a matter of fact, 
in this case double roundabouts deal the best performances, instead Flower roundabouts have an intermediate performances between conventional roundabouts with $(1+1)$ or $(1+2)$ geometry and double lane roundabouts (see Figures 13, 14 and 15). As suggested by Mauro et. al. [11], only when the right-turn percentage is higher or equal to $70 \%$ of the total, flower roundabouts can cause delays and pollutant emissions inferior to those observed in the roundabouts with conventional configurations.

Table 2

Vehicles typology

\begin{tabular}{|c|c|c|c|c|c|c|c|c|c|}
\hline \multicolumn{6}{|c|}{$\begin{array}{l}\text { Passenger cars } \\
\text { [veh/year] }\end{array}$} & \multirow{2}{*}{\multicolumn{3}{|c|}{$\begin{array}{c}\text { Heavy Duty Trucks } \\
\text { [veh/year] }\end{array}$}} & \multirow{3}{*}{$\begin{array}{l}\text { TOT. } \\
\text { [veh/ } \\
\text { year] }\end{array}$} \\
\hline \multicolumn{3}{|c|}{ Benzina } & \multicolumn{3}{|c|}{ Diesel } & & & & \\
\hline $\begin{array}{c}\text { EURO } \\
\text { II }\end{array}$ & $\begin{array}{c}\text { EURO } \\
\text { III }\end{array}$ & $\begin{array}{c}\text { EURO } \\
\text { IV }\end{array}$ & $\begin{array}{c}\text { EURO } \\
\text { II }\end{array}$ & $\begin{array}{c}\text { EURO } \\
\text { III }\end{array}$ & $\begin{array}{c}\text { EURO } \\
\text { IV }\end{array}$ & $\begin{array}{c}\text { EURO } \\
\text { II }\end{array}$ & $\begin{array}{c}\text { EURO } \\
\text { III }\end{array}$ & $\begin{array}{c}\text { EURO } \\
\text { IV }\end{array}$ & \\
\hline 13627 & 8171 & 17590 & 4598 & 10054 & 18860 & 2025 & 2025 & 4050 & 81000 \\
\hline 27253 & 16342 & 35180 & 9197 & 20108 & 37720 & 4050 & 4050 & 8100 & 162000 \\
\hline 68133 & 40855 & 87949 & 22992 & 50270 & 94301 & 10125 & 10125 & 20250 & 405000 \\
\hline 81760 & 49026 & 105539 & 27590 & 60324 & 113161 & 12150 & 12150 & 24300 & 486000 \\
\hline 95386 & 57197 & 123128 & 32189 & 70378 & 132022 & 14175 & 14175 & 28350 & 567000 \\
\hline 122640 & 73539 & 158308 & 41385 & 90486 & 169742 & 18225 & 18225 & 36450 & 729000 \\
\hline 136266 & 81711 & 175898 & 45984 & 100539 & 188602 & 20250 & 20250 & 40500 & 810000 \\
\hline 149893 & 89882 & 193488 & 50582 & 110593 & 207462 & 22275 & 22275 & 44550 & 891000 \\
\hline
\end{tabular}

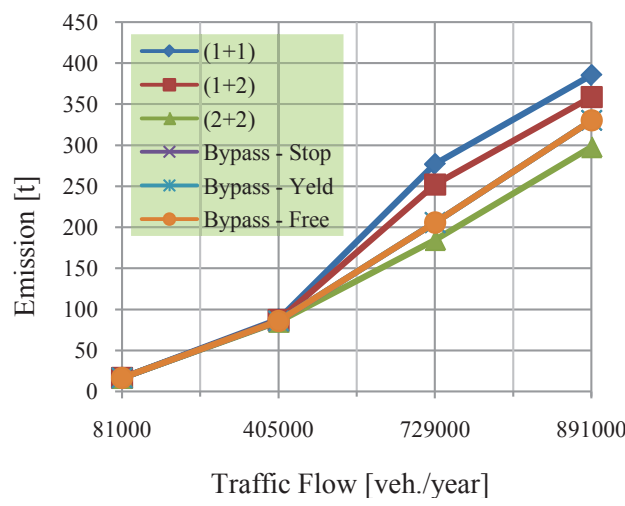

Fig. 19. $\mathrm{CO}_{2}$ emission

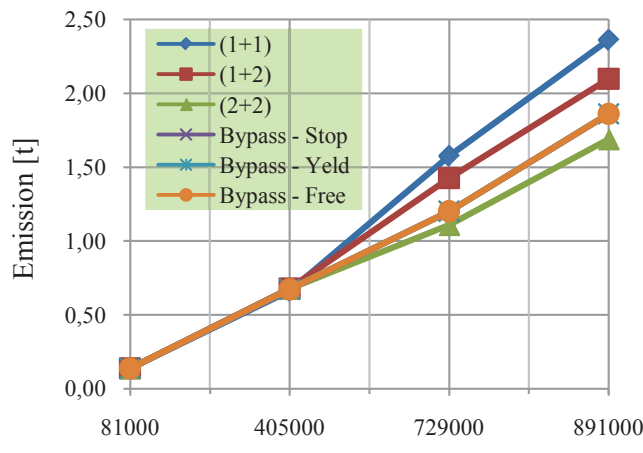

Traffic Flow [veh./year]

Fig. 20. CO emission 


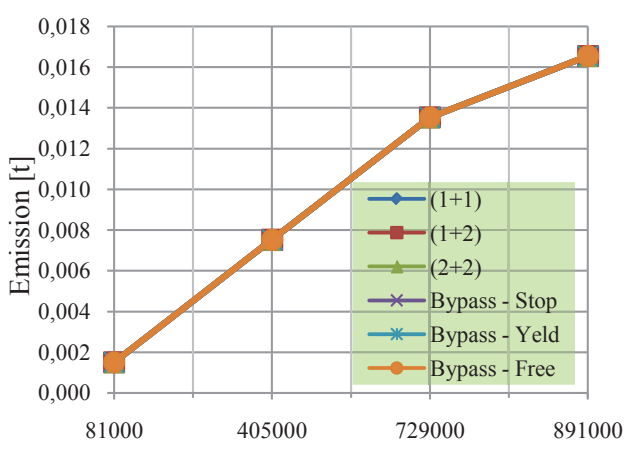

Traffic Flow [veh./year]

Fig. 21. $\mathrm{CH}_{4}$ emission

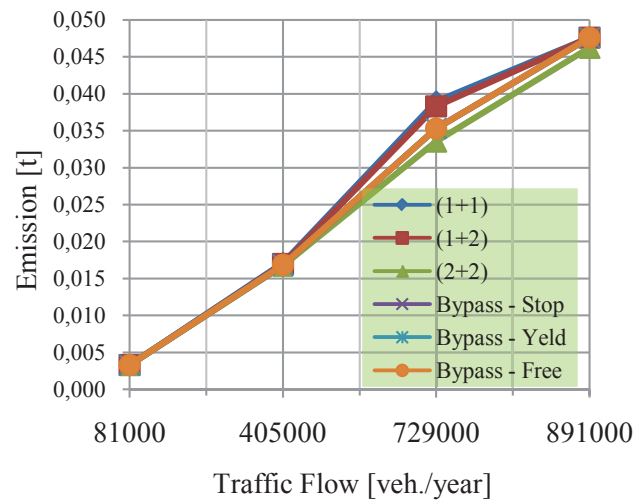

Fig. 23. $\mathrm{PM}_{2,5}$ emission

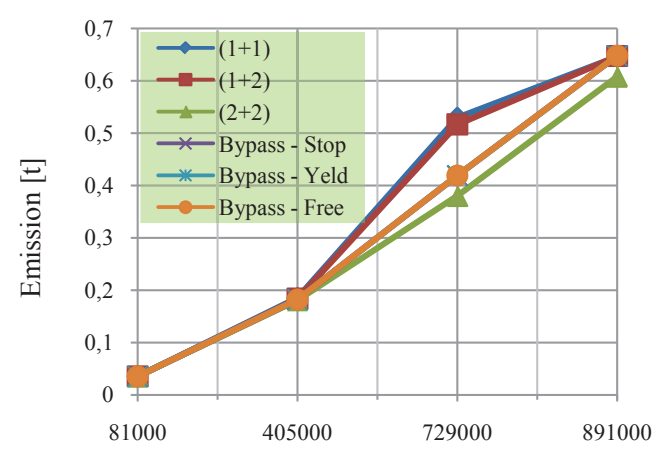

Traffic Flow [veh./year]

Fig. 22. NO emission

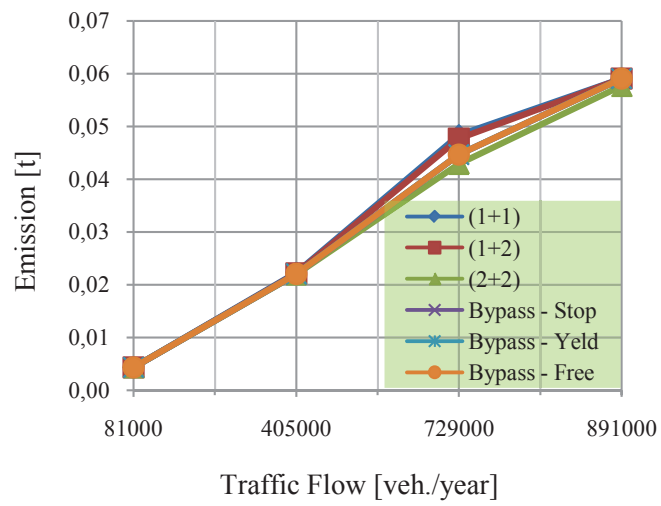

Fig. 24. $\mathrm{PM}_{10}$ emission

\section{Conclusion}

Flower roundabouts represent one of the latest geometric variations of roundabouts; they consist of two entry lanes, two exit lanes and a ring lane but, unlike conventional roundabouts, right-turning vehicles do not get onto the ring because they are properly canalized into a slip lane lane. The geometric configuration and traffic flow regulations allow to eliminate weaving and through conflict points along the circulatory roadway. If we consider the different intensity and location of the conflicting flows in the two entry lanes as well as the modes of traffic regulations, entry capacity can be estimated by carrying out a lane by lane analysis. In any case, it is always possible to determine the entry capacity which appears to be correlated to the circulating flow in front of the 
entry under examination, to the pedestrian flow, to the degrees of saturation of lanes and to the flow exiting from the next arm after that under analysis (following the ring direction). In summary, flower roundabouts can be used whenever the circulating flow is below $1,600 \mathrm{veh} / \mathrm{h}$; up to that threshold, they can lead to higher capacities and lower delay than those in conventional compact roundabouts. Also, when most of users at entries turn on the right (almost $70 \%$ of total entry flow) flower roundabout are the best solution if compared with all conventional layouts. If a circulating flow exceeded $1,600 \mathrm{veh} / \mathrm{h}$, the ring tends to saturation, users can't get into it and consequently entry flows reduce towards zero. Therefore, if circulating flows will likely to be higher than $1,600 \mathrm{veh} / \mathrm{h}$, it is necessary the use of to traditional large-sized roundabout schemes with two ring lanes (for example the double roundabout). With the aim to identify the benefits of innovative roundabouts respect to conventional intersections in terms of road pollution emission, specific traffic analyses have been carried out. In lower traffic conditions there aren't benefits in the use of innovative roundabouts. When the traffic intensity is high (up to $450000 \mathrm{veh} / \mathrm{year}$ ), road emissions are function of the roundabouts geometry. In this case, double roundabouts give the best performances, instead Flower roundabouts have an intermediate performances between conventional roundabouts with $(1+1)$ or $(1+2)$ geometry and double lane roundabouts. Only when the right-turn percentage is higher or equal to $70 \%$ of the total flower roundabouts can cause delays and pollutant emissions inferior to those observed in the other configurations examined.

\section{REFERENCES}

1. T. Tollazzi, M. Rencelj, S. Turnsek, Slovenian experiences with alternative types of roundabouts - "turbo" and "flower" roundabouts, 8th International Conference May 19-20, 2011, Vilnius, Lithuania, ISBN 978-9955-28-829-9 (3 Volume).

2. T. Tollazzi, M. Rencelj, S. Turnsek, New Type of Roundabout: Roundabout with "Depressed” Lanes for Right Turning - "Flower Roundabout", Promet - Traffic\&Transportation, Vol. 23, 2011, No. 5, 353-358.

3. T. Tollazzi, M. Rencelj, S. Turnsek, G. Jovanovic, Krožno križišce s pritisnjenimi pasovi za desno zavijanje: patentna prijava št. P-201000026, 28.01.2010. Ljubljana: Urad RS za intelektualno lastnino, 2010.

4. R. Mauro, M. Cattani, Model to evaluate potential accident rate at roundabouts, Journal of Transportation Engineering, Volume 130, Issue 5, September 2004, Pages 602-609. ISSN: 0733947X, DOI: 10.1061/(ASCE)0733-947X(2004)130:5(602).

5. M. Guerrieri, D. Ticali, F. Corriere, F. Galatioto F, Flower roundabouts: estimation of capacity and level of service, GSTF Journal on Computing (JoC), June 2012, Vol. 2, n. 2, Print ISSN: 2010-2283, E-periodical: 2251-3043 (pag. 101-106) - doi: 10.5176/2010-2283_2.2.175.

6. R. Mauro, F. Branco, Comparative Analysis of Compact Multilane Roundabouts and TurboRoundabouts, Journal of Transportation Engineering, 136(4), Pages 316-322. ISSN: 0733947X, doi: 10.1061/(ASCE)TE.1943-5436.0000106.

7. R. Mauro, M. Cattani, M. Guerrieri, Potential accident rate of turbo-roundabouts, The Baltic Journal of Road and Bridge Engineering, ISSN 1822-427X print, ISSN 1822 (in press). 
8. F. Corriere, M. Guerrieri, Performance analysis of basic turbo-roundabout in urban context. Procedia - Social and Behavioral Sciences, Volume 53, 3 October 2012, Pages 622-632, Elsevier, ISSN: 18770428. http://dx.doi.org/10.1016/j.sbspro.2012.09.912.

9. HCM 2010, Highway Capacity Manual. Transportation Research Board, edition 2010, TRB.

10. R. Akcelik, Roundabout model calibration issue and a case study, TRB National roundabout conference, USA, 22-25 May 2005.

11. R. Mauro, M. Guerrieri, Right-turn bypass lanes at roundabouts: geometric schemes and functional analysis. Modern Applied Science, ISSN 1913-1844 (Print) ISSN 1913-1852 (Online), Canadian Center of Science and Education, Vol. 7, No. 1, pp. 1-12, doi:10.5539/mas.v7n1p1.

12. "Roundabouts: An Informational Guide - Second Edition" ( NCHRP REPORT 672), TRB, 2010.

13. M. Tracz, Analysis of Small Roundabouts' Capacity, 2008 National roundabout conference, Kansas City, Missouri.

14. M. Tracz, J. Chodur, K. Ostrowsk, Roundabouts Country report-Poland, $6^{\text {th }}$ International Symposium on Highway Capacity and Quality of Service, Stockholm, June 2011.

15. M. Tracz, S. Gaca, Recent developments in highway geometric design in the reconstruction of the polish road network - country report, $4^{\text {th }}$ International Symposium on Highway Geometric Design, June 2nd-5th 2010 Valencia, Spain.

16. R. Mauro, Calculation of roundabout, Berlin-Heidelberg: Springer, 2010, 169 p. - (engineering). - ISBN: 978-3-642-04551-6 online. - DOI: 10.1007/978-3-642-04551-6.

17. W. Brilon, B. Stuwe, O. Drews, Sicherheit und Leistungsfähigkeit von Kreisverkehrsplätzen, Institute for Traffic Engineering, Ruhr Universität, Bochum, Deutschland, 1993.

18. R. Mauro, M. Guerrieri. Flower roundabouts: performances analysis and comparison with conventional layouts. European Journal of Scientific Research, ISSN: 1450-216X/1450-202X, Volume 94 Issue 2, January 2013, pp. 242-252, EuroJournals Publishing, Inc. 2012.

19. F. Corriere, D. Di Vincenzo, M. Guerrieri. A logic fuzzy model for evaluation of the railway station's practice capacity in safety operating conditions. Archivers of Civil Engineering, ISSN: 1230-2945, LIX, 1, 2013, pp.3-19.

20. M. Guerrieri, D. Ticali. Sustainable mobility in park areas: the potential offered by guided transport systems. International Conference on Sustainable Design and Construction, March 23-25, 2011, Kansas City, Missouri, ASCE (2012). Vol. ICSDC 2011: Integrating Sustainability Practices in the Construction Industry- pp. 661-668, ISBN 9780784412046, ASCE Conf. Proc. doi:10.1061/41204(426)81.

21. D. Gkatzoflias, C. Kouridis, L. Ntziachristos, Description of new elements in COPERT 4 v9.0, EMISIA SA Report, No: 11.RE.005.V1.

22. F. Corriere, G. Peri, V. La Rocca, Characterization of Biodiesel from Vegetable Oil Using Comprehensive Two-Dimensional Gas Chromatography, Applied Mechanics and Materials Vols. 260-261 (2013) pp 312-317, ISSN: 1662-7482, doi:10.4028/www.scientific.net/AMM.260-261.312.

23. F. Corriere, G. Peri, V. La Rocca, G. Rizzo, Environmental Implications of Traffic Flow Delays: a Model for Urban Streets, Applied Mechanics and Materials Vols. 260-261 (2013) pp 1167-1172, ISSN: 1662-7482, doi:10.4028/www.scientific.net/AMM.260-261.1167.

24. R. Mauro, M. Cattani, Functional and Economic Evaluations for Choosing Road Intersection Layout. Promet-Traffic\&Transportation, Vol 24, No 5. DOI: http://dx.doi.org/10.7307/ptt.v24i5.1180. 